\title{
Notocampsis Townes (Cryptinae, Ichneumonidae, Hymenoptera) do Paraná, Brasil ${ }^{1}$
}

\author{
Vinalto Graf $^{2}$ \\ Alice Fumi Kumagai ${ }^{3}$
}

\begin{abstract}
Notocampsis Townes (Cryptinae, Ichneumonidae, Hymenoptera)
from Paraná, Brazil. N. ferruginea sp. nov., is described from Brazil and a key of identification of the species is presented. The new species is from Paraná (São José dos Pinhais, Jundiaí do Sul).

KEY WORDS. Hymenoptera, Ichneumonidae, Cryptinae, Notocampsis, new species
\end{abstract}

Notocampsis é um gênero de ichneumonídeo da subfamília Cryptinae (HANSON \& GAULD 1995; = Gelinae, TOWNES 1970), relativamente raro nas coleções. Notocampsis incliva Townes, 1970, espécie tipo do gênero, foi coletada em Nova Teutônia (Seara), Santa Catarina, por Fritz Plaumann em 1955. Em 1993 duas espécies do Paraná foram descritas: N. santaclarae Graf, 1993 e N. umuaramae Graf, 1993. No estudo de Notocampsis da coleção do Departamento de Zoologia da Universidade Federal do Paraná se localizou mais uma espécie do Paraná - São José dos Pinhais, Jundiaí do Sul - que se descreve a seguir. Os espécimens estão depositados na coleção de Entomologia Pe. J.S. Moure, Universidade Federal do Paraná, Curitiba (DZUP). As medidas são em milímetros e a terminologia segue TOWNES (1969), HANSON \& GAULD (1995) e GRAF (1993).

\section{Notocampsis ferruginea sp. nov.}

Figs 1-4, 6-7

Holótipo fêmea. Cabeça preta, mesosoma ferrugíneo-enegrecido; pernas e tergitos ferrugíneos (Fig. 1); antenas com 23 flagelômeros, do sexto ao décimo amarelo-pálidos; escapo, margem distal do pedicelo, face externa subdistal da mandíbula e labro na sua margem distal, ferrugíneo-amarelados; palpos, tégulas, pernas 1,2 e 3 nas coxas, trocanteres, trocantelos, margem distal da coxa 3 e parte proximal da tíbia 3 e seus esporões, amarelo-pálidos; asas transparentes; o segundo tergito com fina margem distal amarela, tergitos posteriores (quarto ao sétimo) amarelados (Fig. 4); escutelo, na sua margem posterior, áreas membranosas das partes esternais e valvas do ovipositor, amareladas; ovipositor ferrugíneo. Cabeça com a altura 0,72 vezes a largura $(0,96: 1,34)$, a distância ocelocular quase igual a

1) Contribuição número 1365 do Departamento de Zoologia, Universidade Federal do Paraná.

2) Departamento de Zoologia, Universidade Federal do Paraná. Caixa Postal 19020, 81531-980 Curitiba, Paraná, Brasil.

3) Departamento de Zoologia, Universidade Federal de Minas Gerais, Caixa Postal 486, 31270-970. Belo Horizonte, Minas Gerais. Brasil. E-mail: acfk@ mono.icb.ufmg.br

Revta bras. Zool. 19 (4): 1177 - 1180, 2002 
interocelar $(0,12: 0,14)$; olho com comprimento, em vista lateral, 0,54 vezes a altura $(0,40: 0,74)$; escrobo antenal com pontuação densa com os intervalos lisos iguais ou pouco menores que o diâmetro dos pontos; acima dos alvéolos antenais algumas rugas transversais e entre os alvéolos, rugas verticais; sulco fraco no meio da fronte, abaixo do ocelo médio; face e clípeo contínuos e convexos no meio, com densas rugas transversais, e nos lados com rugas inclinadas até os olhos, clípeo na margem distal fracamente côncavo e brilhante; área malar larga $(0,18)$ (Fig. 2), com sulco subocular fracamente em arco, do olho à base da mandíbula; gena lisa e brilhante, com pontuação muito fina e esparsa, mais densa no vértice, seu comprimento 0,60 vezes o do olho $(0,24: 0,40)$, em vista dorsal; carena occipital unida à base da mandíbula, incompleta lateralmente; labro aplanado, liso e brilhante, com pontos grossos e esparsos, o bordo distal reto; antena com 23 flagelômeros, do $11^{\circ}$ ao $20^{\circ}$ aplanados no lado ventral; escapo com bordo apical fracamente oblíquo, segundo flagelômero com a largura 0,70 vezes o comprimento $(0,14: 0,20)$; mandíbula plana na base, com pontuação grossa e esparsa na metade basal, o dente inferior pequeno, o superior mais longo e largo, com a margem distal em bisel, o seu bordo superior diferenciado em ponta. Mesoscuto com comprimento menor que a largura $(1,04: 1,16)$, a parte anterior do lobo médio e lobos laterais com pontuação fina; a área média posterior com pontos alongados muito densos, anastomosados (Fig. 3), na área próxima ao sulco escuto-escutelar com pontos muito finos e esparsos; notáulices curtos $(0,24)$, bem impressos; escutelo arredondado, liso, brilhante e com pilosidade esparsa, carena escutelar irregular não alcançando o ápice; escrobo pronotal liso e brilhante, com rugas na metade superior; esternaulo curto, 0,23 vezes o comprimento da mesopleura $(0,24: 1,04)$; mesopleura com rugas delicadas na frente da proeminência alar, látero-ventralmente com pontuação fina e esparsa e na parte superior lisa e brilhante; metapleura na margem inferior com rugas, na superior com pontuação finíssima e esparsa; coxa posterior com rugas finas, paralelas nos lados mesal e dorsal, sua face externa com pontuação densa; asa anterior com a veia cu-a (nérvulo) distal à origem da veia Rs+M (basal) quase 0,50 vezes seu comprimento; aréola alar 1,54 vezes $(0,34: 0,22)$ mais larga que longa (Fig. 7$)$, com a veia $2 \mathrm{r}-\mathrm{m}$ bem menor que $3 \mathrm{r}-\mathrm{m}$ (intercubital); asa posterior com a parte proximal da veia $\mathrm{Rs}$ quase igual a r-sm; a veia cu-a (nervelo) interceptada pela $\mathrm{Cu}$ (discoidela) próximo da A. Propódeo com área basal mais longa que larga $(0,32: 0,22)$ (Fig. 6), a área peciolar com largura 0,65 vezes o comprimento $(0,40: 0,62)$, lisa, com pontuação finíssima e esparsa; apófises propodeais longas e largas; espiráculos propodeais pequenos, ovalados, com a largura metade do comprimento $(0,06: 0,12)$. Metasoma com primeiro tergito estreito, liso e brilhante (Fig. 6), com poucas cerdas esparsas, sua largura proximal 0,28 vezes a largura distal $(0,16: 0,56)$ e esta 0,44 do seu comprimento $(0,56: 1,26)$; ovipositor laminar, liso, com o comprimento quase duas vezes a altura do metasoma.

Comprimentos total $4,83 \mathrm{~mm}$, da asa anterior $4,67 \mathrm{~mm}$, da tíbia posterior $2,12 \mathrm{~mm}$.

Macho. Difere da fêmea nas antenas, filiformes, afinadas para o ápice, escapo, pedicelo e flagelômeros proximais amarelados, os seguintes mais escuros. Tergitos quarto ao sétimo e cláspers amarelados. Palpos, tégulas, coxas, trocanteres 



Figs 1-9. Holótipo fêmea de Notocampsis ferruginea sp. nov.: (1) corpo em vista lateral; (2) mandíbula com dente superior em bisel, escapo, pedicelo e área malar; (3) mesoscuto, escutelo e área basal do propódeo; (4) ovipositor e últimos tergitos do metasoma; (6) coxa posterior com finas rugas e primeiro tergito do metasoma; (7) asas, com aréola da asa anterior larga. Notocampsis santaclarae: (5) mandíbula com linha mediana de pontos com cerdas; (9) ovipositor. Notocampsis umuaramae: (8) asas.

e trocantelos das pernas 1 e 2, e os trocanteres posteriores, amarelo-esbranquiçados. Asas tingidas fracamente de amarelo.

Holótipo. Fêmea, Brasil, Paraná: São José dos Pinhais (Serra do Mar, Estrada Br 277, km 54, malaise), 06-13.VIII.1984, CIIF (Centro de Identificação de Insetos Fitófagos). Parátipos: do mesmo local 1 fêmea 03-10.IX.1984 e 9 machos: 1 03-10.IX.1984, 1 10-17.IX.1984, 2 24.IX-01.X.1984, 1 01-08.X.1984, 1 15.IX. 1986, Jundiaí do Sul, Fazenda Monte Verde, 3 machos 04.VIII.1986, Profaupar (Levantamento da Fauna Entomológica do Paraná) (Malaise). Holótipo e 10 parátipos no DZUP. 
Discussão. Notocampsis ferruginea sp. nov. está morfológicamente mais próxima de $N$. santaclarae do que das outras espécies de Notocampsis pelo dente superior das mandíbulas em bisel e as coxas posteriores com finas rugas paralelas, mas difere desta espécie pelo ovipositor mais longo e delgado e pela ausência de linha mediana de pontos com cerdas nas mandíbulas.

Etimologia. Nome aposto, refere-se à cor ferrugínea, presente no mesosoma e metasoma.

\section{Chave para identificação das espécies de Notocampsis}

1. Mandíbula com dente superior com margem distal em bisel (Fig. 2); coxas posteriores com finas rugas paralelas (Fig. 6) $\ldots \ldots \ldots \ldots \ldots \ldots \ldots 2$

1'. Mandíbula com dente superior afilado; coxas posteriores sem rugas paralelas . .

2. Ovipositor longo, o comprimento quase duas vezes a altura do metasoma (Fig. 4); face externa da mandíbula sem linha mediana de pontos com cerdas; palpos, tégulas, coxas anteriores e medianas amarelo-pálidos a esbranquiçados; mesosoma ferrugíneo-enegrecido, tergitos metasomais ferrugíneo-amarelados ............................. ferruginea sp. nov.

2'. Ovipositor curto, o comprimento menor que a altura do metasoma (Fig. 9); face externa da mandíbula com linha mediana de pontos com cerdas (Fig. 5); palpos, tégulas, coxas anteriores e medianas ferrugíneos a enegrecidos; mesosoma preto, metasoma ferrugíneo a ferrugíneo-amarelado . ......... ................................... santaclarae Graf, 1993

3. Veia anterior da aréola mais curta que a posterior; asa posterior com a parte proximal da veia Rs com comprimento quase igual a rs-m; escrobo pronotal com rugas em toda sua extensão; área basal do propódeo mais longa que larga, com sua carena posterior reta; mesosoma preto .............. ................................. incliva Townes, 1970

3'. Veia anterior da aréola igual a posterior; asa posterior com a parte proximal da veia Rs mais longa que a rs-m (Fig. 8); escrobo pronotal com rugas na parte superior; área basal do propódeo mais curta que larga, com carena posterior em arco; mesosoma ferrugíneo ............... umuaramae Graf, 1993

\section{REFERÊNCIAS BIBLIOGRÁFICAS}

Graf, V. 1993. O gênero Notocampsis (Ichneumonidae, Hymenoptera) no Paraná, Brasil. Acta Biol. Paranaense, Curitiba, 22 (1-4): 63-69.

Hanson, P.E. \& I.D. Gauld. 1995. The Hymenoptera of Costa Rica. Oxford, Oxford Univ. Press, 893p.

Townes, H. K. 1969. The Genera of Ichneumonidae. Part 1. Mem. Amer. Entomol. Inst., Gainesville, 11: $1-300$. $1-537$.

Recebido em 09.VII.2002; aceito em 05.XI.2002. 